\title{
GENERIC AND SPECIFIC INFLUENCES OF NUTRITION IN THE TOTAL SUPPORT OF ARTHRITICS*
}

\author{
By RALPH PEMBERTON AND C. WESLER SCULL
}

STUDIES of patients with chronic arthritis reveal that they have disturbances not only in the joints but also in the major systems of the body. It is conceivable that the systemic manifestations of the disorder are referable to deviations of function secondary to some central factor. Information on this possibility, however, is not sufficiently well developed to establish such an hypothesis as fact. In any event the clinical syndrome of arthritis cannot now be regarded as a symptom-complex produced by a single extraneous agent or agency, such as infection. It is, indeed, recognised that many factors are operative in bringing about the syndrome. It appears reasonable, therefore, at least for the present, to consider the disorder, not as a consequence of a partial attack by a single ætiologic agent, but rather as a resultant of the cumulative effects of a " total war" waged by various contributing factors, with varying emphasis, respectively, upon and in the body as a whole. Any therapeutic regimen to be regarded as satisfactory must, therefore, combat not only one but all of the impinging destructive agencies. Measures directed toward single deviations characterising the disease (that is, partial support) are usually inadequate, except by chance. Active intervention must proceed against all directly destructive or subversive influences within the body, such as physical fatigue, anæmia, nervous or endocrinous imbalance, faulty nutrition, postural defects and focal infection. In short, a programme of therapy to be effective must involve " total support" of the patient. "Total support" implies and may be defined as a correlation of various therapeutic procedures which, applied singly, may be of slight avail in arresting the disease, but when applied in co-ordination and appropriately are of great and apparently unappreciated value.

Added significance attaches to the conception of "total support " of the arthritic in that the doctrine of focal infection,

* Received for publication February 21, 1942. 
important though it be, has undergone, at least in the United States, a revision downward. Depreciation of this factor as the main ætiologic and therapeutic influence in arthritis necessitates, as a consequence, fuller recognition of the many factors operative, at least in a contributory way, in the symptomatology of the disease.

While such considerations may appear self-evident to the thoughtful observer, certain of them are inadequately evaluated. This is especially true of nutritional factors. These should be considered, however, not as isolated independent factors but as interdependent components of the whole situation and some reference to elemental principles of nutrition will be necessary in order to present specific recommendations concerning them in proper perspective. "Total support," as defined above, postulates aid to the dysfunctioning systems of the body and, as regards the present thesis, optimal supplies of raw materials for tissue reconstruction. However, the matter cannot be disposed of by so simple a definition and it is not enough to prescribe a well constituted diet. For example, the alimentary tract is often the site of dysfunction, which may condition the efficiency and availability of any diet, however optimal. Again, nutrition is not a function of the gastro-intestinal tract and food alone, and it is commonly overlooked that the finer vascular and lymphatic radicles largely constitute the sites at which nutritive and indeed most vital physiological phenomena actually transpire. Indeed, the larger vessels of the vascular system serve only to bring the fluid to the fixed tissues. The finer vascular and lymphatic channels are usually more or less disturbed in the arthritic syndrome, and it is, by definition, essential in a teleologic sense that the above several systems achieve and maintain optimal function if essential materials are to reach the tissues which need them. These relationships are emphasised because they illustrate an interdependence of various major functions which must be served if the concept of total support is to be actually achieved. Certain specific individual ends are also to be served by adjusted alimentation, but it is not as a single measure, intended alone to control certain phases of the clinical problem, but, also, as an important feature of the several essential parts of " total support," that dietetic regulation should be included in the therapeutic regimen for arthritics. In the opinion of the writers the principles underlying treatment of the 
arthritic syndrome are essentially similar for both great types. This statement is not to be interpreted too literally: thus, rest to the atrophic (rheumatoid) arthritic, if improperly conducted, may lead to ankylosis, whereas rest to the hypertrophic (osteo-) arthritic never does. However, rest is nevertheless essential in the treatment of each type. It may be remarked here that some years ago the American Committee for the Control of Rheumatism openly proclaimed its view that arthritis, including both great types, is a systemic disease with joint manifestations. Hypertrophic (osteo-) arthritis of purely traumatic nature, such as the tennis elbow, is obviously not included in the above generalisation. The process of atrophic arthritis (rheumatoid) is supposed to partake of an " inflammatory" nature, and hypertrophic (osteo-) arthritis of a "degenerative" nature, but it is possible to place undue emphasis upon the separation of these two types. Degenerative processes involve factors which are poorly understood and may be no more than the manifestations in later life of factors which in earlier life induce youthful types of reactions.

A further consideration in the application of nutritional regulation to the syndrome of "rheumatism" is that the symptom-complex of arthritis is not always the same in patients presenting rheumatic complaints. The qualitative nature and quantitative extent of nutritional imbalance vary widely. This situation requires an appraisal of the individual nutritive state in each patient. Those practitioners who, on a priori grounds, accept no measure as significant unless it is equally applicable to all cases, naturally regard such efforts toward optimal nutrition as a waste of time. It is to be noted, however, that " economy of hypothesis" is permissible only where the members of a class under discussion are alike in all particulars-i.e., are fully described by a single variation from normal. Even the most superficial survey of any large group of atrophic or rheumatoid arthritics reveals extreme variations in clinical and pathological patterns. The maximum benefit from dietetic control can be secured only when such control is directed toward specific as well as toward generic objectives. The prescription of a " good diet," like the prescription of rest, without bearing in mind the favourable or unfavourable influence of the components of rest, may wholly miss the intended mark.

The inter-relationship between nutritive needs and physical activity is one of the most clearly established principles of bio- 
chemistry, and the importance of nutritional deficiencies is becoming more generally appreciated. The clinical implications inherent in the above principles are often ignored, however, and patients are sometimes advised to keep physically active while following restricted rations. The influences of over-alimentation are even less widely recognised, and the error of placing a patient in bed and over-feeding him is not uncommon. This has been exemplified, not infrequently, in the treatment of patients with pulmonary tuberculosis.

Under ordinary conditions of good health the disposal of surplus materials does not present a serious problem. However, the tissues of the arthritic are often already the site of surfeits in the form of extra fluids and other tissue "detritus". Furthermore, the alimentary tract is often atonic as a whole. . The gastric secretion is frequently hypochlorhydric, the gall-bladder may be sluggish, and the colon is often enlarged. A recent roentgenographic study (Spackman, E. W., Bach, T. F., Scull, C. W., Pemberton, R., "Complete Roentgen Ray Studies of the GastroIntestinal Tract in 400 Arthritics," Am. Journ. Med. Sc., 202, [July] 68, 1941) of the gastro-intestinal tract in 400 arthritics revealed evidence of deviations from normal structure or function of the stomach, gall-bladder and small intestine in 60 per cent. of the cases. The most notable abnormalities were encountered in the colon, 80 per cent. of the cases presenting a pattern of ptosis, dilatation and/or atony. While the full significance of these abnormalities is not yet clear, there can be no reasonable doubt that the margin of functional efficiency involved is smaller than in the normal subject. The absorption and disposal of surplus foodstuffs by an overtaxed organism creates unnecessary demands in the form of extra physiological work, a cost which the already fatigued and dysfunctioning organism can ill afford.

These considerations are of more than academic interest, as can be seen from the experience of one of the writers' patients. This subject, a young male atrophic spondylitic, was brought to a state of symptomatic equilibrium through a balanced programme. After a period of clinical quiescence the caloric value of the diet was increased by 350 calories. A mild exacerbation followed this change in the patient's regimen. A reduction to the lower basal level was followed by a remission in the symptoms of pain and stiffness. Further comparatively precise adjustments of the caloric intake were uniformly charac- 
terised by the same sequence of exacerbation and remission. While only a few cases in the writers' experience have shown the same critical response to a small caloric adjustment, many have presented equally dramatic symptomatic responses to brief periods of sharply reduced caloric intake. Clinical exploitation of this relationship is most favourable, and should be conducted only when the patient is at rest in bed and all accessible contributing factors have been cared for. Operation of the influences involved has been widely recognised in the dramatic but ephemeral improvement which, chiefly because of the necessarily lowered food intake, often follows major abdominal operations.

Extended and uncritical use of sub-maintenance diets may lead to unhappy results. A certain American physician, recently deceased, developed a wide following among the laity in both the U.S.A. and England, largely upon the basis of the clinical benefits following restricted dietaries_-applied, however, without adequate discrimination as to the eligibility of the patient for such nutritional strains. Another sub-maintenance dietary practice is a so-called "Hollywood" diet, recommended as a reducing programme, and rheumatics are alleged to be relieved of their stiffness and pain by this measure. Whatever other factors may be operative, allegedly or otherwise, the individual improvement experienced by some followers is undoubtedly due to the curtailment of calories with a necessarily attendant release of tissue surfeits. However, the general application of such measures, indiscriminately and without consideration of the complete clinical situation, is wholly unwarranted and hazardous. The orthodox profession is to be blamed if, by indifference to significant physiological influences, it drives the laity to unscrupulous practitioners who apply these influences unwisely. Indeed, the origin of such cults as osteopathy, cheiropraxy, and the like is to be found in comparable obloquy by the profession towards limited but basic influences in the field of physical therapy.

As a practical empirical approximation, the caloric value of the diet for the non-febrile arthritic patient of essentially normal weight at rest in bed is placed at 10 per cent. over the calculated basal energy output. For the ambulatory patient such a restricted intake would lead to caloric imbalance and loss of weight. For the grossly underweight patient, or the patient who is febrile, this quantity would be inadequate. Adjustments of the calories to meet such necessities must be made. 
The patient with rheumatic disease presents several features which emphasise the importance of directing special attention to the amount and quality of proteins in the dietary. The atrophic (rheumatoid) arthritic often presents evidence of a systemic deficiency of protein. The muscles are atrophic or wasted. Whether this condition arises from increased demands for protein materials or from disuse, a term which merely indicates an involuntary but purposeful loss of metabolically active material, makes no practical difference. Furthermore, impaired skeletal integrity in arthritis is often evidenced by decreases in inorganic salts, and it seems probable that demineralisation is secondary to changes in the organic matrix of bone which consists largely of proteins. This possibility is suggested by observations by Clark on the X-ray diffraction patterns of the bone matrix in animals with rickets. These diffraction patterns are distinctly different from normal. No direct data on the diffraction patterns of arthritic bones have been recorded so far as the writers are aware.

In addition to the foregoing evidences of protein imbalance in the arthritic, subnormal quantities of cystine in the fingernails have been observed. While this deviation is by no means confined to patients with arthritis, it does reflect some disturbance of nutrition of these structures. It may be observed incidentally that attempts by the writers to produce evidence of articular damage by feeding to rats diets extremely low in lysine and cystine have been negative. Such experiments, however, do not demonstrate that deficiencies of amino acids do not contribute to arthritic pathology.

The fluid tissues likewise present evidence of disturbances in protein metabolism. Many patients, particularly severe atrophics (rheumatoid cases), show marked anæmia. The pathogenesis of the associated anæmia in the arthritic is not fully clear. It appears likely that the reduced number of cells in the peripheral blood is in part a consequence of the disordered bone marrow from which springs the granulation tissue and endosteal activity characteristic of atrophic (rheumatoid) arthritis. While this anæmia is " secondary" in one sense, efficient restoration of the hæmoglobin level depends upon an adequate supply of dietary protein of good biological quality. Similarly patients who have been ill for prolonged periods often present a lowered level of plasma albumin. This reduced level of albumin is partially, though not wholly, responsible for the tendency toward a low- 
grade generalised œdema shown by these patients. While the low plasma protein is probably to be attributed to "toxic" influences rather than a primary dietary deficiency, the most efficient means of restoring toward normal this situation centres around a sufficient supply of the raw materials from which albumin is elaborated.

Contrary to a still popular belief, arthritics, except for the few who have gout, show no evidence of a disorder in purine metabolism. There is thus no reason for limiting the supply of nucleoproteins. Neither is there, any substantial reason for excluding red meats from the diet of the arthritic. In order to secure the most satisfactory supply of amino acids the protein component of the diet should be secured from a variety of sources. Not less than 1 gram of protein per kilogram of body weight is desirable for the average arthritic patient. For the severely malnourished subject the amount provided should be larger.

The carbohydrate fraction usually provides a large proportion of the calories in the average dietary, especially in the less favoured classes. The influence of excess or inadequacy of carbohydrate is usually regarded as limited to questions of over and under weight. Apart from this generally recognised relationship, however, divergent views are expressed as to the best level for this dietary factor in the regimen of the arthritic. On the one hand it is alleged that the arthritic can ingest a "high" carbohydrate diet without handicap, inasmuch as the respiratory quotient of the arthritic is normal, thus indicating a normal capacity for the oxidation of carbohydrate. On the other hand there is strong clinical evidence to suggest, and there is also strong physiological justification for the view, that the rate of convalescence of certain arthritics may be accelerated by diets comparatively low in concentrated carbohydrate foodstuffs.

A number of dietaries have been employed as part of the treatment of arthritics which differ from average rations in several particulars. Dorothy Hare (D. C. Hare, Journ. Amer. Med. Assoc., London Letter, 1937, 1108, 308) employed a diet consisting of raw vegetables of low sodium chloride content and including approximately equivalent amounts of fats and carbohydrates. Significant clinical improvement was noted in eight of twelve patients under this regimen. A somewhat similar dietary programme has been advocated by Gerson (M. Gerson, Münch. Med. Wchnschr., 1930, 77, 967). Both Gerson and Hare 
attribute the benefits derived by their patients to the low sodium content of the foods. Hare further believes that the comparatively high amounts of vitamins $\mathrm{B}$ and $\mathrm{C}$ contribute to the favourable influence. Pevsner et al. (M. J. Pevsner, B. T. Talalaev, G. L. Levin, J. J. Bouten, A. J. Lacharova, Appendix, Acta Rheumat., 1934, 2021, 7) have employed low carbohydrate diets, composed chiefly of vegetables, with beneficial results which they attribute to desensitising influences. It is to be noted, however, that these dietaries are characterised by under-maintenance or mere-maintenance levels which have certain necessary consequences, to be discussed presently.

The interdependence of specific nutritional factors has been shown by Cowgill (G. R. Cowgill, " The Vitamin B Requirement of Man," Yale University Press, New Haven, 1935), who demonstrated that vitamin B requirement is quantitatively related to the total energy turnover. Not only the absolute but also the relative demand for vitamin $B$ is raised with increased energy expenditure and increased caloric intake. Whether the primary cause for the elevation of energy turnover is a pyrogenic facior or simply an elevation in physical activity, makes no difference so far as the increased need for vitamin $B$ is concerned.

The clinical corollary of this principle has been clearly stated by Spies (T. D. Spies, D. P. Hightower, L. H. Hubbard, "Some Recent Advances in Vitamin Therapy," Journ. Amer. Med. Assoc., July $27,1940,115,295$ ), in respect to the remission of symptoms and disorders arising from nutritional deficiencies, such as pellagra: "in many cases lesions heal following rest in bed." In addition to the clinical evidence of improvement following reduced physical activity and caloric exchange, Spies and his colleagues have observed that even when a diet remains inadequate with respect to certain components of the vitamin $B$ complex, rest in bed is followed by an elevation of the concentration of coenzymes in the blood.

It is evident that carbohydrates are not to be regarded as harmful per se to arthritics. However, there are clear-cut indications in the case of arthritics for keeping the carbohydrate fraction within certain limits. The first of these is a fortuitous one. Concentrated carbohydrate foodstuffs carry very small or negligible amounts of vitamins and minerals. When purified carbohydrates are extremely high in a diet it becomes difficult to secure an adequate vitamin intake from other foodstuffs. 
The second indication for keeping the carbohydrate fraction within certain limits depends upon the unfavourable influence of excessive amounts of carbohydrate upon the low-grade œdema of the arthritic, to which attention has been directed by Scull and Pemberton (C. W. Scull, R. Pemberton, "The Influence of Dietetic and other Factors on the Swelling of Tissues in Arthritis," Ann. Int. Med., 1935, 8, 1247). A significant control of this œdema can be effected by keeping the carbohydrate fraction at a comparatively low level. In this respect a low carbohydrate diet exerts an influence comparable to that of a low sodium

Low Calorific Diets. Relatively Low Carbohydrate Diets.

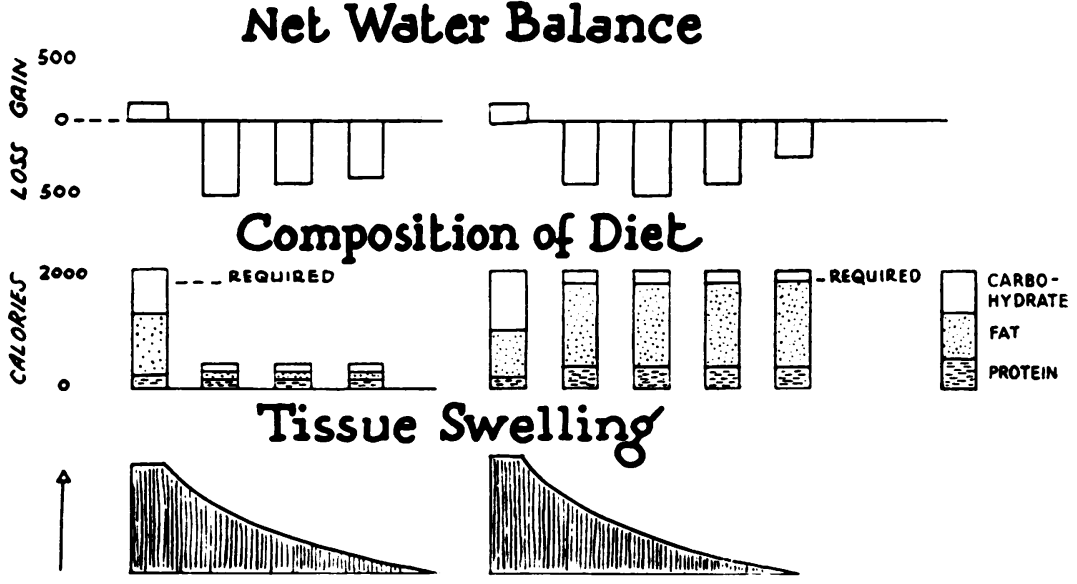

Diagram showing Effect of some Dietary Factors on Water Loss and Tissue Swelling in Arthrits.

Representative data on metabolic studies of arthritic patients showing that tissue swelling may be reduced during periods characterised by losses of water from the body. This may occur with sub-maintenance feedings or on diets which are calorically adequate but in which the proportions of fats and proteins to carbohydrates are comparatively high.

chloride diet. Carbohydrates, when stored or retained in the body in the form of glycogen or glucose, hold four times their weight of water. Fats hold only one-tenth and proteins are stored only exceptionally.

In view of these several considerations it appears desirable in most cases to supply from one-third to one-half of the calories in the form of carbohydrates. Furthermore, it is generally advisable to supply the bulk of the carbohydrates in the form of vegetables and fruits which contain not more than 15 per cent. of this foodstuff. This latter provision helps to assure an adequate 
intake of vitamins. Exceptions to these generalisations will be pointed out in the subsequent text.

The remainder of the caloric quota in the dietary of arthritics is of course to be derived from fats, which should afford from onehalf to two-thirds of the total calories. From the standpoint of the conditions usually presented by arthritics, this adjustment of the three foodstuffs provides certain desiderata. The above diet is not sufficiently high in fat to be ketogenic, but it does tend in this direction and thus further counteracts, to this extent at least, the low-grade œdema of the arthritic. Furthermore, there is exercised an appreciable sparing action on the demands for vitamin B. Fats bearing appreciable amounts of fat-soluble vitamins should be chosen, such as butter and lard, not only because of these important materials but also because of their content of essential unsaturated fatty acids. There are few arthritic patients unable, because of limited gastro-intestinal function, to handle diets of this high fat content. When this is the case, however, digestive disturbances prevent the beneficial metabolic influences and such diets are then contra-indicated. In addition patients with gout are alleged to undergo exacerbation following the ingestion of large amounts of fat. Except for these comparatively small groups a diet moderately high in fat is usually well suited to the needs of the patient. While hypertrophic arthritics frequently present elevations in the level of cholesterol in the blood, this in itself does not provide sufficient grounds for keeping the fats at a low level.

At the possible risk of stating what may appear to be axiomatic in the rôle of accessory food substances, it is desirable to review at this point a few relevant factors which may have large significance in therapy. There is no evidence that any class of arthritics has its complete origin in a deficiency of any one of the known accessory foodstuffs, but there are certain symptoms which may conceivably have their origin in such deficiencies.

While evidences of deficiency of vitamin A do not dominate the symptom-complex of arthritis, there are clinical indications for the administration of liberal quantities of preformed vitamin $\mathbf{A}$ in the programme of total support. The hepatic dysfunction observed among atrophic arthritics* emphasises the necessity

* J. S. Davis, “The Liver an Etiologic and Therapeutic Factor in Certain Types of Blood Disease and in Gout and Gouty Arthritis"; Proc. A.R.A., Journ. Amer. Med. Assoc., 1941, 117 (November), 1147. 
for providing vitamin A rather than its precursor the provitamin carotene.

Symptoms conceivably referable to vitamin B deficiency are encountered with considerable frequency among arthritics. A lack of appetite with decreased gastro-intestinal motility is notably common. Symptoms suggestive of peripheral neuritis may be present. The low-grade peripheral œedema above described may be due, in part, to the same mechanism that leads to the odema seen in wet beri-beri. The ptotic and atonic colon of the arthritic mentioned earlier in this text has been regarded by Fletcher (A. A. Fletcher, Journ. Lab. and Clin. Med., 1930, 15,1140 ) as probably due to a deficiency of vitamin B. These several deviations have often yielded to adjustments of the physiologic demands by means of rest, the reduced total caloric turnover, and the low carbohydrate, high fat diet referred to in the afore-mentioned text.

The connective tissues of the arthritic show a generalised laxity, which may be related to vitamin $\mathrm{C}$ deficiency. The gums of arthritics are quite frequently the site of infection; the gingivæ are swollen, tender and spongy. While this situation involves infective factors, it is possible that the infection is in a sense secondary to disordered physiology of the tissues. Muscular weakness and tenderness is another symptom of many arthritics which may conceivably be induced by a relative deficiency of ascorbic acid.

It is notable that arthritics show on the average lower than normal values for ascorbic acid in the blood. Furthermore, larger quantities of ascorbic acid are required by many atrophic arthritics than by normal subjects to increase the renal output over basal levels. Following the ingestion of vitamin $\mathrm{C}$ these subjects show a lesser rise in the level of ascorbic acid in the blood than do normal subjects. This increased tolerance or decreased level of tissue saturation is not pathognomonic for arthritis, but -may be present when the basal supply of vitamin $\mathrm{C}$ is on a level adequate only for the normal subject.

In addition to these clinical data, Rinehart (J. F. Rinehart, Annals Int. Med., 1935, 9, 586) and his associates have observed lesions in experimental animals maintained upon sub-optimal supplies of vitamin C, bearing a remarkable similarity to those found in atrophic arthritis. While pathologists are not all agreed that the features of the experimental syndrome are identical with those of the clinical variety, there can be no 
reasonable doubt that the primary tissue defects arising from vitamin C deficiency could "pave the way" for the development of many aspects of the arthritic syndrome.

The symptom of skeletal atrophy or demineralisation is conspicuous in atrophic arthritis. Attention has therefore been directed to the possible rôle of vitamin D. Recent claims as to the specific efficacy of extremely large doses of modified sterols related to vitamin $D$ in the treatment of arthritis have not been widely substantiated and rather lie outside the realm of nutritive considerations.

The average mixed diet provides an abundant supply of minerals. There is little precise evidence to indicate that the arthritic has specialised requirements for any one of them. The general demineralisation of the skeleton of the atrophic arthritic and the local and occasional systemic trends in hypertrophic arthritics in the same direction may be regarded as emphasising a need for calcium and phosphorus. The anæmia of the chronic arthritic suggests an increased requirement for iron. While a reduced metabolic rate may arise from an iodine insufficiency there is little evidence to suggest such a pathogenesis for the reduced metabolic rate encountered among rheumatics.

The acid base residues of ordinary diets are suitable for arthritics who have reasonably satisfactory renal function. By this token special therapeutic claims for alkalising diets or supplements seem unwarranted. Certainly arthritics as a class do not present notable evidence of systemic acidosis. Hare (loc. cit.) and Gerson (loc. cit.) have attributed the favourable influences of certain vegetable dietaries to low sodium and high potassium contents. Both of these factors would tend to favour the reduction of extra-cellular tissue water, previously discussed. It may be noted that comparable influences upon extra-cellular fluid are involved in the use of external heat with sweating, purgation-both of which may be drastic and ephemeral in their results-massage, and the use of diuretics. As noted earlier, sub-maintenance levels of calories, or low-carbohydrate, high-fat rations, achieve the same result. Any regimen involving submaintenance must be entered upon with great caution. A sharply lowered caloric intake is usually more of academic than of clinical interest and one merit of the high-protein, high-fat, low-carbohydrate diet discussed is that it can be continued indefinitely, at any desired caloric level, without danger. 
Water can be provided the arthritic ad lib., consistent with renal function. The low-grade œdema shown by some rheumatics is best regulated by control of substances which "hold" water rather than by limitation of water intake. It may be observed in passing that water may be lost from body tissues even on a fluid diet. The Karrel diet of milk, for example, leads to a net water loss from the body, partly because of its caloric inadequacy and partly because of its high protein and low carbohydrate content.

The bulk-i.e., the amount of indigestible residues—of dietary materials plays a rôle in gastro-intestinal motility. Arthritics presenting stasis are often benefited in this respect by foods with bulky residues. However, a considerable proportion of chronic rheumatic patients have digestive tracts abnormally irritable at some segment and are handicapped rather than benefited by this measure. While a few arthritics have a specific sensitivity to certain foodstuffs, this situation is comparatively rare and in any event must be handled as an individual problem.

Occasionally a dislike for certain classes of foodstuffs or an ill-advised restriction of foodstuffs may give rise to or contribute toward a nutritional deficiency. In addition to these habitual or artificial conditions, the chronically ill patient often develops a genuine anorexia. Under these circumstances tonics, supplementary amounts of vitamin $B$, or, rarely, insulin may be indicated as specific stimulants to appetite.

\section{SUMMARY}

The sick arthritic presents a symptom-complex which must be regarded as a resultant of the cumulative effects of a "total war," by various factors, upon major aspects or systems of the body. Effective therapy requires a regimen of "total support" of the patient. There are obviously two therapeutic aspects to total support: one, in general, removes from the field such accessible factors as make for or constitute worry, fatigue, faulty body mechanics and focal infection; the other seeks to provide constructive factors such as rest, correction of anæmia, replacement therapy in the gastro-intestinal or endocrine system; tonic medication, sedation, physical therapy and optimal nutrition. Obviously these objectives and measures overlap.

Among the factors which, like rest, have widest application to arthritics as a group, is that of optimal nutrition, using that 
term in a refined sense. Specific influences on the arthritic manifestations as well as generic influences may be achieved.

The arthritic presents atrophy of bone and muscle, anæmia, modified plasma protein and peripheral œedema. The correction of these disturbances requires by definition a diet which differs from that adequate for the individual in health. In addition to these systemic disturbances, the gastro-intestinal tract of arthritics as a group shows evidence of both anatomic imbalance and functional disturbance. Under such circumstances more than ordinary care is necessary in the provision of nutritive materials required for the maintenance, repair and reconstruction of tissue, whether damaged directly by faulty nutrition or indirectly as a result of the disease.

There are suggestive data indicating that certain symptoms encountered with significant frequency among arthritics may arise from partial vitamin deficiencies. Under such conditions, and indeed in most cases, the foodstuffs should be so balanced as to decrease rather than increase the demands for vitamins. Even in health the ration of vitamin to calories, not merely the amount of vitamins, must increase as the total calories increase. In view of the composition of the average dietary this usually requires that the carbohydrate be relatively reduced. Appropriate supplements of vitamins are also indicated.

The low-grade cedema characterising many or most arthritics is open to influence by rest and also by such drastic and ephemeral measures as sweating and purgation. Another and safe influence, however, is available through a dietary which makes away from rather than towards fluid retention. For this as well as for the afore-mentioned reasons, the dietary for the arthritic should be in general high in protein, reasonably high in fat, and somewhat restricted in concentrated carbohydrate foodstuffs.

Under ordinary circumstances, caloric requirements of the arthritic patient at rest in bed are met by the calculated basal output plus 10 per cent. Ample provision of biologically good protein (at least 1 gram per kilogram body weight) is indicated not only to meet immediate needs, but to replenish depleted atrophic tissues. The calories from carbohydrate should constitute from 35 per cent. to 50 per cent. of the total. The balance of the caloric quota is provided for by fats. Obvious exceptions to this generalisation are indicated for the grossly underweight or overweight patient, and for patients who have an 
intolerance for fatty foods, though the principles involved in the above general distribution of the foodstuffs have application to nearly all cases. The arthritic requirements for other dietary factors-viz., minerals, water, bulk and palatability-present no great departures from the usual.

When dietary supplies are adjusted to optimal levels, as above described, and in co-ordination with the demands of the arthritic, conditions are most favourable for convalescence. While recovery will occur in certain patients without taking these factors into account, in others it is of crucial or paramount importance. There are few, if any, arthritic cases in which the rate of recovery cannot be expedited by co-ordinating dietetic measures, as above described, with the many other agencies necessary in achieving "total support" of the patient.

Neglect of the physiological influences upon the arthritic syndrome, available through purposive dietary adjustments, has led to the development of cults in which under-nutrition or even starvation constitutes a routine therapeutic procedure. This uncritical application of certain nuclei of truth succeeds therapeutically in some cases robust enough to tolerate it and accounts for the success of such movements. It results in great injustice to asthenic arthritic subjects, however, and will probably continue to do so until the orthodox profession concerns itself more with the issues at stake.

\section{FIBROSITIS}

A Biographical Study of Fifty Civitian and Mmitary Cases, From the Rheumatic Unt, St. Stephen's Hospital (London County Councit), and a Mmitary Hospital

By PHILIP ELLMAN, OSWALD A. SAVAGE, E. WITTKOWER, AND T. F. RODGER

Fibrositis, a well recognised scourge of mankind, is certainly one of the commonest of the rheumatic diseases and is responsible for much social and economic disturbance. Davidson and Rae stated that in 1936 there were among the insured population of Scotland (35 to 40 per cent. of the total population) " no fewer than 50,000 cases" of rheumatism in its various forms which 